\title{
Importance of NS5 protein for Zika virus survival
}

\section{Hesham Elshahawi $^{1}$, Sharifah Syed Hassan ${ }^{1,2}$ and Vinod Balasubramaniam ${ }^{1 *}$}

1Jeffrey Cheah School of Medicine and Health Sciences, Monash University Malaysia, Jalan Lagoon Selatan, Subang Jaya 47500, Selangor, Malaysia

2Tropical Medicine \& Biology Multidisciplinary Platform, Monash University Malaysia, Jalan Lagoon Selatan, Subang Jaya 47500, Selangor, Malaysia

*Author to whom correspondence should be addressed.

* Correspondence: vinod.balasubramaniam@monash.edu

\begin{abstract}
ZIKV is the latest addition to an ever-growing list of arboviruses that are causing outbreaks with serious consequences. 14 mild cases were recorded between 1960 and 1980 until the first major outbreak was recorded in 2007 on Yap island followed by more severe outbreaks in French Polynesia (2013) and Brazil (2015) leading to a 20-fold increase in GBS and Microcephaly cases respectively. Various transmission methods have been recorded ranging from Aedes mosquito vector transmission to sexual and vertical transmission. No current vaccines or treatments are available but recent studies have taken interest in the NS5 protein which has both the RdRp \& MTase domains making it important for viral replication alongside other important functions such as inhibiting the innate immune system thus ensuring virus survival and replication. Structural studies can help design inhibitors while biochemical studies can help understand the various mechanisms utilized by NS5 thus counteracting them can inhibit or abolish the viral infection. Finally, drug repurposing has also proven to be an effective tool since hundreds of thousands of compounds can be screened in-silico thus saving time and resources while also having information available on such compounds especially if they are already used to treat other ailments.
\end{abstract}

Keywords: Zika; NS5; Flavivirus; Arbovirus; TBK1; STAT2; IFN1; IFN3; RdRp; MTase

\section{Introduction:}

Zika virus (ZIKV) is a single stranded positive sense RNA arbovirus belonging to the Flaviviridae family alongside Dengue, Yellow fever, and West Nile viruses [1]. The $11 \mathrm{~kb}$ RNA strand has a single open reading frame (ORF) that is flanked by a $5^{\prime} \& 3^{\prime}$ untranslated regions that assist in translation (refer to figure 1). The ORF codes a single polyprotein that is processed and cut to yield 3 structural proteins: $\mathrm{C} \rightarrow$ Capsid, prM $\rightarrow$ Pre-membrane, $\mathrm{E} \rightarrow$ Envelope and 7 non-structural proteins: NS1, NS2A, NS2B, NS3, NS4A, NS4B \& NS5 [2,3]. Like other arboviruses, ZIKV is found in sylvatic cycles with the occasional human infection via bite of an infected female Aedes mosquito [4,5]. The virus incubates for 5-10 days in the mosquito's midgut before invading the salivary glands thus infecting its next host as the mosquito feeds [6,7]. Finally, non-vector transmission routes have also been recorded, this includes sexual, vertical (between mother \& fetus) and through various bodily fluids [8-10]. 
Figure 1. Shows the ZIKV single stranded positive RNA with its single ORF flanked by the 5' and 3' UTR regions. The regions coding for the structural and non-structural proteins are shown as well as the individual proteins.

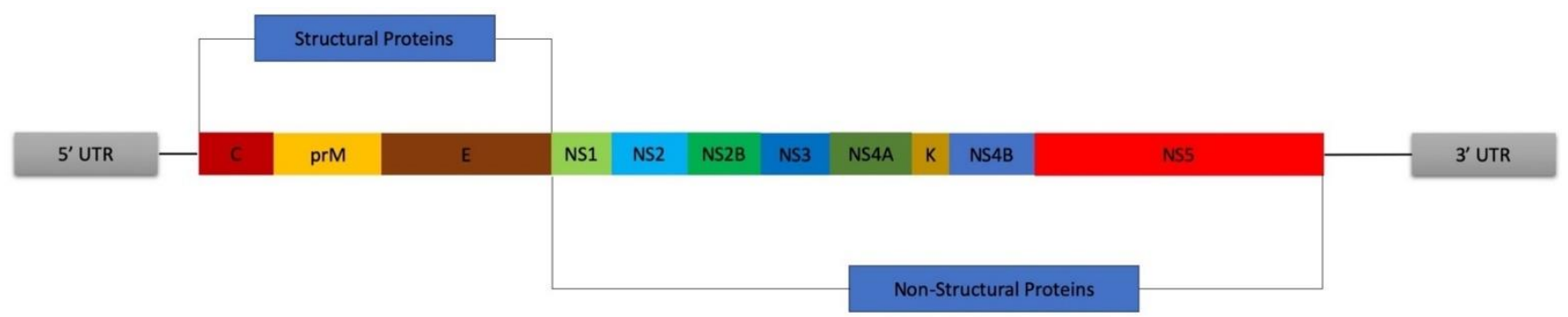

ZIKV was first isolated from Rhesus monkey 766 in the Zika forest in Uganda in 1947 as part of a Yellow fever surveillance study [11]. This was followed by the first recorded human infections in 1952 in Uganda and Tanzania [12-14]. 14 Sporadic cases were reported between the 1960s \& 80s without serious implications since the disease presented as a self-limiting febrile illness [15,16]. The year 2007 marked the first ZIKV outbreak and spread outside of Africa and Asia with 49 confirmed and 59 suspected ZIKV cases being reported on Yap island. Duffy et al. estimated that approximately $3 / 4$ of the population above 3 years of age showed serological evidence of a recent ZIKV infection [16]. This was followed by a second outbreak in French Polynesia in 2013 which swept across the Pacific affecting multiple islands including Cook Islands, New Caledonia, Fiji, Samoa, the Solomon Islands and Easter Island before finally reaching the Americas by 2015 as predicted [14,16,17].

The 2013 outbreak led to an increased interest in ZIKV since this was the first time the virus was linked to hospitalisation and neurological complications; recorded cases in French Polynesia only affected 3\% of the population but led to hospitalisation and a 20 fold increase in reported cases of Guillain-Barre syndrome (GBS) [18]. Brazil suffered heavily by the epidemic since there has been a 20 fold increase in microcephaly and approximately 1.3 million reported cases of autochthonous infection [19]. Finally, the outbreak reached the USA by 2015 [20] and started declining worldwide by the end of 2016 without any signs of resurgence [21].

\section{NS5:}

\section{Protein structure:}

The non-structural protein 5 (NS5), is the largest product coded by the ZIKV RNA being around 904 amino-acids long [22,23]. NS5 consists of 2 domains that enhance each other's functions; an RNAdependent RNA polymerase (RdRp) domain at the C-terminal connected via a linker to a Methyltransferase (MTase) domain at the N-terminal. This makes the NS5 important for viral replication, survival and immune system evasion alongside other roles [24-28]. Zhao et al. found that the ZIKV NS5 protein shares a lot of structural similarities with the Japanese encephalitis virus (JEV) due to conserved residues in the loops and beta sheets forming the MTase domain [28].

\section{Viral Replication:}

Potisopon et al. found that both the RdRp and MTase domains interact with one another to increase the efficiency of RNA replication in DENV; once the RdRp domain begins with RNA synthesis, the first stage involves synthesising primers complementary to the $3^{\prime}$ end of the genome followed by a conformational change in a transition phase to be able to elongate the RNA. Experiments comparing the speed of each phase between a recombinant NS5 and the RdRp domain showed that the MTase domain is required to increase the efficiency of initiation, priming and 
elongation (6-17 folds higher). A similar outcome was observed in ZIKV NS5 by Zhao et al. and the same can be said for other Flavivirus NS5's [26,28].

The NS5 MTase domain has been observed by Issur et al. to work alongside NS3 to form the virus' capping mechanism; NS5 is a true guanylyl-transferase while the NS3 acts as the RNA triphosphatase (RTase) in the reaction [23]. This is important in preventing the newly formed mRNA from being detected and degraded by the innate immune system while also ensuring its translation by the host translation machinery [29]. The first step involves the hydrolyses of the Adenosine nucleotide in the initiating position at the $5^{\prime}$ end of the RNA by the NS3 RTase. Following that, the NS5 MTase forms an enzyme-substrate complex with a GMP molecule which is followed by transferring the GMP to the 5' diphosphate end of the RNA and finally the methylation of the cap at the $2^{\text {nd }} \mathrm{OH}$ (2'OMTase activity by NS5) using S-Adenosyl methionine (SAM) as a methyl donor. Furthermore, allosteric enhancement of the NS5 reaction via binding to NS3 at the linker between the RdRp and MTase domains was observed with a maximum increase of 6-fold [23].

\section{ZIKV and the Innate Immunity:}

\section{Activation of IFN signalling:}

After a viral infection, the body relies on its innate immune system to hold the infection at bay while the adaptive immune system can launch a more effective response. Once ZIKV enters a cell, its RNA is released, and replication factories are assembled at the evaginations of the Endoplasmic Reticulum. The newly synthesised RNA has a 5'-triphosphorylated end which is an example of a pathogen associated molecular pattern (PAMP). RIG-1 and MDA5 are important Pathogen recognition receptors (PRRs) which detect the nascent 5'-triphosphorylated RNA and activate the mitochondrial anti-viral signalling (MAVS) protein. Once MAVS is active, a downstream signalling cascade recruits TNF receptor associated factors (TRAF's) 2, 3 and 6 leading to the activation of TANK-binding Kinase 1 (TBK1) thus phosphorylating and translocating Interferon regulatory factors $3 \& 7$ (IRF3 \& 7) to the nucleus to activate the transcription of IFN1 \& 3 [30-34].

IFN1 consists of IFN alpha \& beta whereas IFN3 is also known as IFN lambda. Both IFN1 \& 3 act directly by massing an anti-viral response while stimulating the adaptive immune system to design antibodies targeting ZIKV. As seen in figure 2, IFN1 \& 3 bind to different receptors; IFNAR1 \& 2 for IFN alpha \& beta whereas IFN3 binds to the IFNLR1 and IL10R2 receptors, each receptor pair forms a heterodimer on the cell surface. Once activated, both receptor pairs follow a similar downstream signalling cascade as seen again in figure 2. This involves recruiting, phosphorylating and the heterodimerization of JAK1 \& TYK2 leading to the phosphorylation and heterodimerization of STAT1 \& STAT2. IRF9 binds to the STAT1/STAT2 heterodimer forming the ISGF3 complex which migrates to the nucleus and binds to various Interferon Stimulated Response Elements (ISREs) thus transcribing various proteins that deal with the ZIKV infection [35,36]. Zhou et al. conducted a gene 
array study to determine if both IFN1 \& 3 activated different genes but found that all of IFN3's targets are also activated by IFN1 [37].

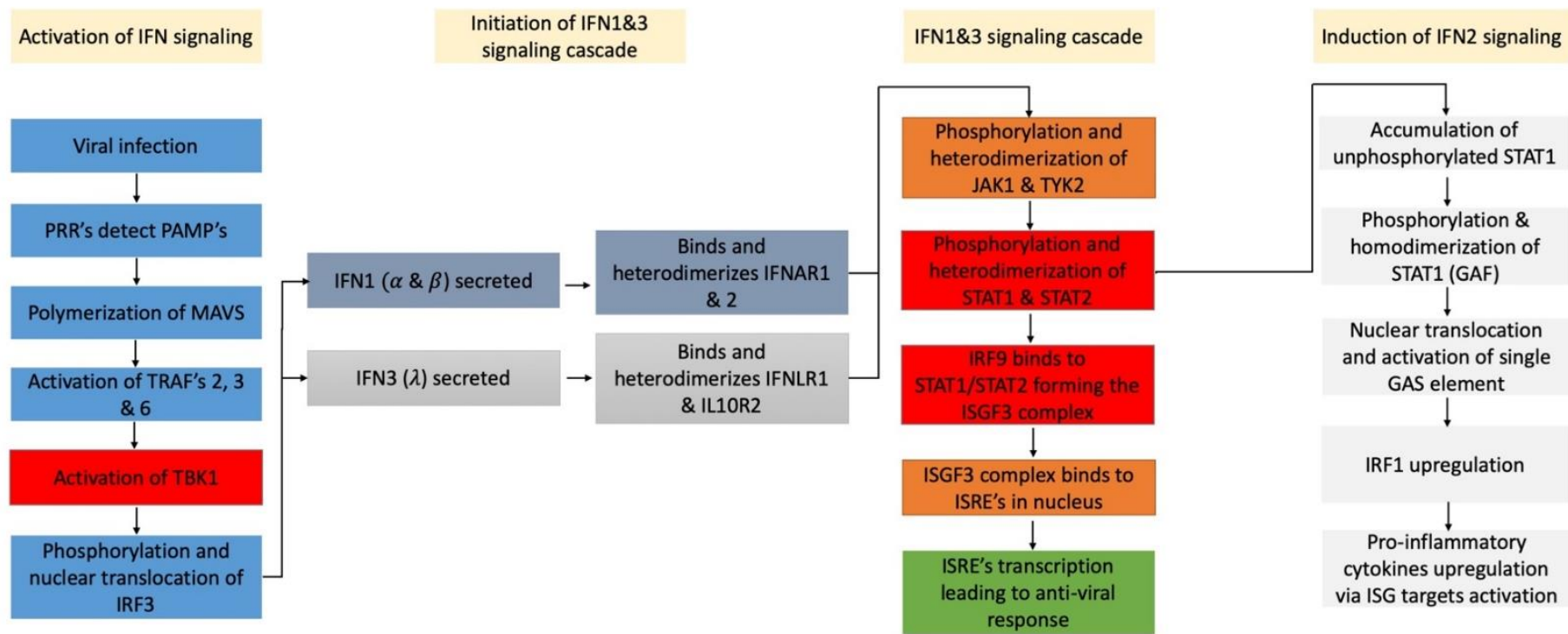

Figure 2. Shows the cascade of events that leads to IFN mediated anti-viral response. The blue pathway leads to the phosphorylation and nuclear translocation of IRF3 thus activating the transcription of the IFN1 $\& 3$ genes. This allows the secretion of both IFN's in which they bind to their respective receptors leading to the activation of the JAK1/TYK2 pathway (depicted in orange) that leads to the formation of the ISGF3 complex thus activating ISRE sites resulting in an effective anti-viral response (depicted in green). After STAT2 degradation, STAT1 phosphorylation and homodimerization increases leading to the formation of GAF elements and upregulation of IRF1. This leads to the upregulation of pro-inflammatory cytokines. ZIKV NS5 interferes at the steps colored in red; NS5 binds to TBK1 preventing its phosphorylation and activation by the TRAF's and binds STAT2 and marks it for proteasomal degradation.

\section{NS5 Antagonism of IFN 1 \& 3 signalling:}

Kumar et al. studied the various effects of ZIKV infection on the innate immune system. Their first observation was ZIKV's ability to abolish the host cell's IFN response and signalling; by measuring the levels of Ifnb and Ifit1 using qPCR, they noticed that the peak levels were only attained between $24 \& 48$ hours unlike the control's 12 hours. Hertzog et al. attributed this to the NS5 protein; NS5 binds and marks STAT2 for proteasome-dependent degradation while also lowering STAT1 phosphorylation levels. Furthermore, lower activation levels of the IFIT1 promoter which is both, an ISRE and an IRF3 target shows that the virus is antagonizing the innate immune system at both the induction and effector phases [25,34].

Lin et al. suggested a mechanism by which ZIKV NS5 abolishes the IFN response via an upstream pathway; this involves antagonizing IRF3 thus preventing the transcription of IFN1 \& 3 genes (refer to figure 2). This is attained by preventing the phosphorylation and nuclear translocation of IRF3; IRF3 levels remained constant after infection unlike the 70\% decrease in phosphorylated IRF3. ZIKV NS5 is able to do this by binding to TBK1 via its ULD domain, both the MTase and RdRp domains are required as the absence of one showed no decrease in phosphorylated IRF3. Furthermore, TBK1 binds to the groove formed by the MTase/RdRp linker and forming this complex might interfere with TRAF 6's interaction and binding with the TBK1 SDD domain due to their close proximity. Finally, this leads to the inability to activate TBK1 which in turn cannot phosphorylate, and activate IRF3 thus abolishing IFN1 \& 3 transcription [38]. 


\section{NS5 causes the degradation of STAT2:}

Grant et al. studied the STAT2 degradation mechanism and found that it slightly differs from the mechanism utilised by DENV; ZIKV NS5 does not recruit the E3 ubiquitin ligase UBR4. Furthermore, they concluded that ZIKV NS5 stays in the nucleus until cytosol STAT2 levels increase after which the NS5 exits the nucleus to bind to and degrade the STAT2 thus preventing it from forming the ISGF3 complex and activating ISRE targets. This effect was reversed with the treatment of proteasome inhibitors. In addition to that, NS5 uses its MTase domain to bind to STAT2 preparing it for degradation but requires the full length NS5 to complete the process [24,25]. Finally, ZIKV NS5 only interacts with human and other non-human primate STAT2 and while wild type mice are immune, IFN deficient mice were susceptible to ZIKV infection thus showing the importance of this signalling pathway in fighting infection [24,39].

\section{Selective induction of IFN 2 signalling:}

IFN 2 signalling is also utilised in antiviral activities by transcribing a different subgroup of ISGs that are proinflammatory [34]. Once IFN 2 activates the IFNGR 1 \& 2 receptors, JAK 1 \& 2 are recruited and phosphorylated to prime the IFNGR $1 \& 2$ complex for the Phosphorylation and homodimerization of STAT1 molecules. This forms the gamma activated factor (GAF) which is translocated into the nucleus to transcribe the single GAS element IRF1 [40]. IRF1 targets certain ISG's which transcribe proinflammatory cytokines like CXCL10 and also the upregulation of the ZIKV entry factors AXL, Tyro3 and DC-SIGN [41,42]. The above pathway can be upregulated thus overexpressing IRF1. This is possible without the actual secretion of IFN 2 (refer to figure 2) since there is an accumulation of STAT1 in the cytoplasm due to STAT2 degradation via ZIKV NS5; there is not enough STAT2 to dimerize with STAT1 therefore more STAT1 homodimers will form. This leads to increased inflammation, autophagy and a spike in programmed cellular death thus spreading viral particles to infect nearby cells $[43,44]$.

\section{ZIKV NS5 as an Antiviral Target:}

As seen above, the NS5 protein has various important roles in ensuring the virus replication and survival thus making it an interesting candidate for anti-viral targeting [24,25,34,35,38,43,45]. We have discussed below some of the methods that might prove useful in the pursuit of effective antivirals.

\section{Structural studies:}

Various groups have studied and released the crystalized structures of both the RdRp and MTase domains alongside identifying important and conserved residues. It has been noted that ZIKV NS5 shares a lot of similarities with other flaviviruses such as the $70 \%$ homology of its RdRp with both WNV \& JEV, the ability of its thumb, palm and fingers domains to superimpose on those of DENV $2 \& 3$ and the $76 \%$ \& $81 \%$ similarity of their priming loops respectively. In addition to that, the ZIKV MTase domain was crystalized into a homodimer with both promoters folding in a similar way to DENV3 and WNV. DENV RNA capping analogues, SAM analogues and allosteric inhibitors were found to be more effective inhibitors of the ZIKV MTase. Furthermore, the specificity of SAM analogues can be improved by either utilising the hydrophobic cavity adjoining the SAM binding site which is conserved among flaviviruses or exploiting the positively charged RNA binding tunnel [28,46-49].

Duan et al. studied the structures and inhibitors of the DENV and ZIKV NS5 and found huge similarities including conserved residues among both viruses. This was confirmed when they found that almost all the involved residues in the binding of each domain with known DENV anti-virals 
were conserved. This included the MTase inhibitor compound 10*, the RdRp inhibitor NTD107 and the N pocket inhibitors JJ-31-MG46 and compound 2 [48].

Another study found that the pyridoxine-derived, small molecule, non-nucleoside inhibitor (NNI) DMB213 inhibited the RdRp domain with an IC50 of 5.2 $\mu \mathrm{M}$. DMB213 was originally designed to chelate the divalent metal ions from the active sites of viruses thus making it a direct competitor to the NS5 RdRp's substrate. The docking analysis revealed that DMB213 sits within close proximity to the active site residues D536, D666 and D667 which are known to coordinate the $\mathrm{Mg}^{2+}$ ions thus confirming the chelation mechanism. Finally, the S604T mutation that renders the RdRp immune to sofosbuvir has no effect on DMB213 thus providing an alternative option [50].

Lin et al. screened an anti-infection FDA approved compound library and found a potential ZIKV NS5 RdRp inhibitor; 10-undecenoic acid Zinc salt (UA) which is currently an over the counter anti-fungal and anti-viral cream. They found that UA is a strong, direct, NNI of the RdRp domain with an $\mathrm{IC}_{50}$ of 1.13-1.25 $\mathrm{MM}$. Docking analysis revealed that UA coordinates with residues D535, D665 and D666 at the active site but only interacted with residues D535 and C667 via a Hydrogen and a covalent bond respectively. Furthermore, residue D535 was mutated to A535 while residue D692 (outside the active site) was mutated to A692. This led to the weak binding of UA to the RdRp since A535's IC50 was 20-fold higher while A692's IC 50 remained unchanged compared to the wild type RdRp thus proving that residue D535 is critical for UA binding [51].

\section{Biochemical studies:}

Rusanov et al. observed a key interaction between the MTase and RdRp domains that affects RNA elongation. Residues E112, P113 and L115 from the MTase domain interact with residue F466 on the RdRp domain to stabilise the F motif. Mutations introduced at these residues significantly lowered RNA elongation but had no effect on initiation. Motif F forms the top part of the NTP entry tunnel and the above residue interactions ensure its correct orientation. Furthermore, this feature seems to be virus specific due to differences in the arrangement of the RdRp subdomains but drugs can be designed to interfere with this interaction thus inhibiting viral replication [52-54].

The NS3 helicase has an important function in ZIKV replication as it is responsible for unwinding the newly synthesised dsRNA. Due to its low efficiency after unwinding 18 base pairs, there has to be a mechanism that enables it to unwind the $11 \mathrm{~kb}$ genome. Xu et al. observed an interaction between NS3 and NS5 that increases NS3's dsRNA unwinding capability and found that abolishing this interaction via mutations in the NS3 C-terminal was sufficient to disrupt ZIKV replication [55]. In addition to that, it is safe to assume that drugs designed to target the NS3 Cterminal residues 303-618 and the RdRp domain residues 320-368 [56] can abolish this interaction therefore inhibiting ZIKV.

Kovanich et al. recently conducted a ZIKV and JEV interactome study that identified 137 human proteins that interact with NS5 (81 were novel). They also constructed a protein-protein interaction map consisting of 115 unique proteins with a total of 421 interactions, most of which were accumulated within spliceosome related proteins. Furthermore, flavivirus NS5 was shown to interact with some of the proteins that make up the Paf1 complex. It was found that inhibition of this complex increased infectivity of ZIKV and DENV but inhibited JEV thus showing that some host proteins interact differently with different flaviviruses [57]. Finally, NS5 is highly conserved among different Flaviviruses $[24,45,48,58]$ so identifying possible host protein interactions might prove an effective way to develop anti-virals. 


\section{Drug repurposing:}

Another interesting venue involves repurposing drugs. Hundreds of thousands of drugs can be screened against ZIKV NS5 to test for inhibition. This might include anti-virals, anti-biotics, anticancer and anti-parasitics. Time and resources can be saved since efficacy and safety reports already exist.

One approach is to screen current nucleoside analogues since they have shown their effectiveness in viral inhibition since the 1980's [59]. These are either purine or pyrimidine analogues which mimic their structure to trick the viral RNA/DNA polymerase into incorporating them in the growing chain thus leading to early termination. Other desirable attributes include efficient uptake and activation inside the target cells. Finally, nucleoside analogues have shown a higher affinity towards viral polymerases which might be due to the extensive error-correction mechanisms employed by mammalian cells [60,61].

Sofosbuvir is one of 7 FDA approved NS5 inhibitors that was originally designed to treat Hep C (a Flavivirus). It has successfully shown inhibition towards ZIKV NS5 $[58,62,63]$. This can be attributed to the highly conserved sequence of the flavivirus RdRp that interacts with sofosbuvir. Sacrametno et al. reported that sofosbuvir successfully lowered ZIKV mediated cell death and infectivity in hepatoma, neuroblastoma, neural stem cells and brain organoids thus proving its ability to prevent microcephaly. This was achieved by sofosbuvir's ability to disrupt the Hydrogen bonding network inside the RdRp's active site thus leading to early chain termination. In addition to that, significantly higher A to $G$ mutations were also recorded $[58,64,65]$.

7DMA is another nucleotide analogue that was originally designed for Hep C treatment and was found to inhibit other flaviviruses with $\mathrm{EC}_{50}$ values ranging from $5 \mu \mathrm{M}$ to $15 \mu \mathrm{M}$ [66-68]. This was observed in Eyer et al.'s screening of 29 nucleoside analogues containing various substituents. They found that only 5 analogues were capable of inhibiting ZIKV showing the importance of the 2'C-methyl substitution [69]. These were the 2'-C-methyl substituents 2'-CMA, 7DMA, 2'-CMC, 2'CMG and 2'-CMU with EC 50's of 5.26 $\mu \mathrm{M}, 8.92 \mu \mathrm{M}, 10.51 \mu \mathrm{M}, 2.25 \mu \mathrm{M}$ and $45.4 \mu \mathrm{M}$ respectively [61]. Furthermore, no cytotoxicity was observed except with the $2^{\prime}$-CMC analogue which caused a $30 \%$ reduction in cell viability at $100 \mu \mathrm{M}$ exposure. In addition to that, Zmurko et al. found that 7DMA treatment can be tolerated by AG129 mice while significantly lowering plasma viral loads 3-8 days post infection thus delaying morbidity and death [70].

Galidesivir, also known as BCX4430 is another nucleoside analogue with anti-viral capabilities spanning 8 virus families and was shown to be well tolerated by monkey and rodent models [71,72]. It was found to significantly lower viral loads in plasma, saliva, urine and CSF samples in Rhesus Macaques. Macaques treated within 24 hours of infection either showed low viral loads or none at all while delayed treatment of up to 72 hours offered partial protection with lower plasma viral loads compared to the controls [73]. In addition to that, 7 out of 8 AG129 mice treated with $300 \mathrm{mg} / \mathrm{Kg}$ (high dose) of BCX4430 daily survived unlike all 16 controls which had a median survival of 15.5 days. Mice given a low treatment dose of $150 \mathrm{mg} / \mathrm{Kg} /$ day showed signs of disease after 23 days thus showing BCX4430's ability to delay morbidity onset. Finally, a 24-hour delay in treatment did not affect survival rates while a 5-day delay still significantly delayed mortality [74].

\section{Conclusion:}

ZIKV was not an important human pathogen until the 2007 and 2012 outbreaks when it was linked to GBS and microcephaly. With no assurances of a repeated outbreak not happening in the future and the lack of current treatments, anti-virals need to be developed soon. NS5 has proven in multiple studies its importance for both the survival and infectivity of ZIKV thus making it a prime target for drug development. With its crystalized structure published by multiple groups, anti-virals 
can be designed to either inhibit the RdRp domain or target the various allosteric interactions between NS5 and its cofactors. Another approach involves repurposing current drugs especially those that show anti-NS5 potential in flaviviruses due to the highly conservative nature of the protein. Furthermore, more interactome studies would prove useful as they would help us better understand which host proteins to target causing maximum inhibition to ZIKV. Finally, clinical and safety studies for any potential ant-virals need to be conducted soon alongside the development of treatment protocols in pregnant women.

Author Contributions: "conceptualization, V.B; methodology, V.B. and H.E.; writing-original draft preparation, H.E.; writing-review and editing, V.B., S.S.H. and H.E.; supervision, V.B. and S.S.H.; project administration, V.B. and S.S.H.; funding acquisition, V.B. and S.S.H."

Funding: "This research was funded by seed grant from Tropical Medicine \& Biology Multidisciplinary Platform, Monash University Malaysia".

Acknowledgments: We thank the anonymous reviewer for critical comments and suggestions. We would also like to thank the school and administration staff of Jeffrey Cheah School of Medicine and Health Sciences for their continuous support to this project and lab members of Infectious Disease Laboratory for critically reading this review.

Conflicts of Interest: "The authors declare no conflict of interest."

\section{References:}

1. CDC. Flaviviridae [Internet]. 2013. Available from: https://www.cdc.gov/vhf/virusfamilies/flaviviridae.html

2. Tham HW, Balasubramaniam VRMT, Chew MF, Ahmad H, Hassan SS. Protein-protein interactions between A. aegypti midgut and dengue virus 2: Two-hybrid screens using the midgut cDNA library. J Infect Dev Ctries. 2016/01/01. 2015;9(12):1338-49. Available from: https://www.ncbi.nlm.nih.gov/pubmed/26719940

3. Šebera J, Dubankova A, Sychrovský V, Ruzek D, Boura E, Nencka R. The structural model of Zika virus RNA-dependent RNA polymerase in complex with RNA for rational design of novel nucleotide inhibitors. Sci Rep. 2018;8(1):11132. Available from: http://www.nature.com/articles/s41598-018-29459-7

4. Diallo D, Sall AA, Diagne CT, Faye O, Faye O, Ba Y, et al. Zika Virus Emergence in Mosquitoes in Southeastern Senegal, 2011. Attoui H, editor. PLoS One. 2014;9(10):e109442. Available from: http://dx.plos.org/10.1371/journal.pone.0109442

5. Figueiredo LTM. Human Urban Arboviruses Can Infect Wild Animals and Jump to Sylvatic Maintenance Cycles in South America. Front Cell Infect Microbiol. 2019;9:259. Available from: https://www.ncbi.nlm.nih.gov/pubmed/31380302

6. Li MI, Wong PSJ, Ng LC, Tan CH. Oral Susceptibility of Singapore Aedes (Stegomyia) aegypti (Linnaeus) to Zika Virus. Turell MJ, editor. PLoS Negl Trop Dis. 2012/08/28. 2012;6(8):e1792. Available from: https://www.ncbi.nlm.nih.gov/pubmed/22953014

7. Wong P-SJ, Li MI, Chong C-S, Ng L-C, Tan C-H. Aedes (Stegomyia) albopictus (Skuse): A Potential Vector of Zika Virus in Singapore. Turell MJ, editor. PLoS Negl Trop Dis. 2013;7(8):e2348. Available from: https://www.ncbi.nlm.nih.gov/pubmed/23936579

8. Kumar A, Jovel J, Lopez-Orozco J, Limonta D, Airo AM, Hou S, et al. Human Sertoli cells support high levels of Zika virus replication and persistence. Sci Rep. 2018/04/05. 2018;8(1):5477. Available from: https://www.ncbi.nlm.nih.gov/pubmed/29615760 
9. Paz-Bailey G, Rosenberg ES, Doyle K, Munoz-Jordan J, Santiago GA, Klein L, et al. Persistence of Zika Virus in Body Fluids - Final Report. N Engl J Med. 2018;379(13):1234-43. Available from: https://doi.org/10.1056/NEJMoa1613108

10. Foy BD, Kobylinski KC, Foy JLC, Blitvich BJ, Travassos da Rosa A, Haddow AD, et al. Probable NonVector-borne Transmission of Zika Virus, Colorado, USA. Emerg Infect Dis. 2011/05/03. 2011;17(5):8802. Available from: https://www.ncbi.nlm.nih.gov/pubmed/21529401

11. Dick GW., Kitchen S., Haddow A. Zika Virus (I). Isolations and serological specificity. Trans R Soc Trop Med Hyg. 1952/09/01. 1952;46(5):509-20. Available from: https://www.ncbi.nlm.nih.gov/pubmed/12995440

12. Karkhah A, Nouri HR, Javanian M, Koppolu V, Masrour-Roudsari J, Kazemi S, et al. Zika virus: epidemiology, clinical aspects, diagnosis, and control of infection. Eur J Clin Microbiol Infect Dis. 2018;37(11):2035-43. Available from: http://link.springer.com/10.1007/s10096-018-3354-z

13. MacDonald PDM, Holden EW. Zika and Public Health: Understanding the Epidemiology and Information Environment. Pediatricsf. 2018;141(Supplement 2):S137-45. Available from: http://pediatrics.aappublications.org/lookup/doi/10.1542/peds.2017-2038B

14. Paixão ES, Barreto F, da Glória Teixeira M, da Conceição N. Costa M, Rodrigues LC. History, Epidemiology, and Clinical Manifestations of Zika: A Systematic Review. Am J Public Health. 2016;106(4):606-12. Available from: http://ajph.aphapublications.org/doi/10.2105/AJPH.2016.303112

15. WHO. Zika Virus [Internet]. 2018. Available from: https://www.who.int/news-room/factsheets/detail/zika-virus

16. Duffy MR, Chen T-H, Hancock WT, Powers AM, Kool JL, Lanciotti RS, et al. Zika Virus Outbreak on Yap Island, Federated States of Micronesia. N Engl J Med. 2009;360(24):2536-43. Available from: http://www.nejm.org/doi/abs/10.1056/NEJMoa0805715

17. Vorou R. Zika virus, vectors, reservoirs, amplifying hosts, and their potential to spread worldwide: what we know and what we should investigate urgently. Int J Infect Dis. 2016;48:85-90. Available from: http://dx.doi.org/10.1016/j.ijid.2016.05.014

18. Oehler E, Watrin L, Larre P, Leparc-Goffart I, Lastère S, Valour F, et al. Zika virus infection complicated by Guillain-Barré syndrome - case report, French Polynesia, December 2013. Eurosurveillance. 2014;19(9):20720. Available from: https://www.eurosurveillance.org/content/10.2807/15607917.ES2014.19.9.20720

19. Mlakar J, Korva M, Tul N, Popović M, Poljšak-Prijatelj M, Mraz J, et al. Zika Virus Associated with Microcephaly. N Engl J Med. 2016/02/11. 2016;374(10):951-8. Available from: http://www.nejm.org/doi/10.1056/NEJMoa1600651

20. CDC. Statistics and Maps I Zika virus । [Internet]. 2019. Available from: https://www.cdc.gov/zika/reporting/index.html

21. WHO. Zika Situation Report [Internet]. Who. 2016. p. 1-6. Available from: http://www.who.int/emergencies/zika-virus/situation-report/4-march-2016/en/

22. Piorkowski G, Richard P, Baronti C, Gallian P, Charrel R, Leparc-Goffart I, et al. Complete coding sequence of Zika virus from Martinique outbreak in 2015. New Microbes New Infect. 2016;11:52-3. Available from: http://dx.doi.org/10.1016/j.nmni.2016.02.013

23. Issur M, Geiss BJ, Bougie I, Picard-Jean F, Despins S, Mayette J, et al. The flavivirus NS5 protein is a true RNA guanylyltransferase that catalyzes a two-step reaction to form the RNA cap structure. RNA. 2009;15(12):2340-50. Available from: http://rnajournal.cshlp.org/cgi/doi/10.1261/rna.1609709

24. Grant A, Ponia SS, Tripathi S, Balasubramaniam V, Miorin L, Sourisseau M, et al. Zika Virus Targets 
Human STAT2 to Inhibit Type I Interferon Signaling. Cell Host Microbe. 2016/05/24. 2016;19(6):882-90. Available from: https://www.ncbi.nlm.nih.gov/pubmed/27212660

25. Kumar A, Hou S, Airo AM, Limonta D, Mancinelli V, Branton W, et al. Zika virus inhibits type-I interferon production and downstream signaling. EMBO Rep. 2016;17(12):1766-75. Available from: http://embor.embopress.org/lookup/doi/10.15252/embr.201642627

26. Potisopon S, Priet S, Collet A, Decroly E, Canard B, Selisko B. The methyltransferase domain of dengue virus protein NS5 ensures efficient RNA synthesis initiation and elongation by the polymerase domain. Nucleic Acids Res. 2014;42(18):11642-56. Available from: http://academic.oup.com/nar/article/42/18/11642/2434506/The-methyltransferase-domain-of-denguevirus

27. Zhou Y, Ray D, Zhao Y, Dong H, Ren S, Li Z, et al. Structure and Function of Flavivirus NS5 Methyltransferase. J Virol. 2007;81(8):3891-903. Available from: http://jvi.asm.org/cgi/doi/10.1128/JVI.02704-06

28. Zhao B, Yi G, Du F, Chuang Y-C, Vaughan RC, Sankaran B, et al. Structure and function of the Zika virus full-length NS5 protein. Nat Commun. 2017;8(1):14762. Available from: http://dx.doi.org/10.1038/ncomms14762

29. Daffis S, Szretter KJ, Schriewer J, Li J, Youn S, Errett J, et al. 2'-O methylation of the viral mRNA cap evades host restriction by IFIT family members. Nature. 2010;468(7322):452-6. Available from: http://www.nature.com/articles/nature09489

30. Seth RB, Sun L, Ea C-K, Chen ZJ. Identification and Characterization of MAVS, a Mitochondrial Antiviral Signaling Protein that Activates NF- $\mathrm{B}$ and IRF3. Cell. 2005;122(5):669-82. Available from: https://linkinghub.elsevier.com/retrieve/pii/S0092867405008160

31. Meylan E, Curran J, Hofmann K, Moradpour D, Binder M, Bartenschlager R, et al. Cardif is an adaptor protein in the RIG-I antiviral pathway and is targeted by hepatitis C virus. Nature. 2005;437(7062):116772. Available from: https://doi.org/10.1038/nature04193

32. Kawai T, Takahashi K, Sato S, Coban C, Kumar H, Kato H, et al. IPS-1, an adaptor triggering RIG-I- and Mda5-mediated type I interferon induction. Nat Immunol. 2005;6(10):981-8. Available from: https://doi.org/10.1038/ni1243

33. Xu L-G, Wang Y-Y, Han K-J, Li L-Y, Zhai Z, Shu H-B. VISA Is an Adapter Protein Required for VirusTriggered IFN- $\beta$ Signaling. Mol Cell. 2005;19(6):727-40. Available from: https://linkinghub.elsevier.com/retrieve/pii/S109727650501556X

34. Hertzog J, Dias Junior AG, Rigby RE, Donald CL, Mayer A, Sezgin E, et al. Infection with a Brazilian isolate of Zika virus generates RIG-I stimulatory RNA and the viral NS5 protein blocks type I IFN induction and signaling. Eur J Immunol. 2018;48(7):1120-36.

35. Matthys V, Mackow ER. Hantavirus Regulation of Type I Interferon Responses. Adv Virol. 2012;2012:19. Available from: https://doi.org/10.1038/nri3581

36. Levy DE, Darnell JE. STATs: Transcriptional control and biological impact. Nat Rev Mol Cell Biol. 2002;3(9):651-62. Available from: https://doi.org/10.1038/nrm909

37. Zhou Z, Hamming OJ, Ank N, Paludan SR, Nielsen AL, Hartmann R. Type III Interferon (IFN) Induces a Type I IFN-Like Response in a Restricted Subset of Cells through Signaling Pathways Involving both the Jak-STAT Pathway and the Mitogen-Activated Protein Kinases. J Virol. 2007;81(14):7749-58. Available from: http://jvi.asm.org/cgi/doi/10.1128/JVI.02438-06

38. Lin S, Yang S, He J, Guest JD, Ma Z, Yang L, et al. Zika virus NS5 protein antagonizes type I interferon production via blocking TBK1 activation. Virology. 2019;527:180-7. Available from: 
https://linkinghub.elsevier.com/retrieve/pii/S0042682218303507

39. Miorin L, Laurent-Rolle M, Pisanelli G, Co PH, Albrecht RA, García-Sastre A, et al. Host-Specific NS5 Ubiquitination Determines Yellow Fever Virus Tropism. Williams BRG, editor. J Virol. 2019;93(14):e00151-19. Available from: http://jvi.asm.org/content/93/14/e00151-19.abstract

40. Michalska A, Blaszczyk K, Wesoly J, Bluyssen HAR. A Positive Feedback Amplifier Circuit That Regulates Interferon (IFN)-Stimulated Gene Expression and Controls Type I and Type II IFN Responses. Front Immunol. 2018;9(MAY):1-17. Available from: https://www.frontiersin.org/article/10.3389/fimmu.2018.01135/full

41. Plazolles N, Humbert J-M, Vachot L, Verrier B, Hocke C, Halary F. Pivotal Advance: The promotion of soluble DC-SIGN release by inflammatory signals and its enhancement of cytomegalovirus-mediated cis -infection of myeloid dendritic cells. J Leukoc Biol. 2011;89(3):329-42. Available from: http://doi.wiley.com/10.1189/jlb.0710386

42. Hamel R, Dejarnac O, Wichit S, Ekchariyawat P, Neyret A, Luplertlop N, et al. Biology of Zika Virus Infection in Human Skin Cells. Diamond MS, editor. J Virol. 2015;89(17):17. Available from: http://jvi.asm.org/lookup/doi/10.1128/JVI.00354-15

43. Chaudhary V, Yuen K, Chan JF-W, Chan C, Wang P-H, Cai J-P, et al. Selective Activation of Type II Interferon Signaling by Zika Virus NS5 Protein. Williams BRG, editor. J Virol. 2017;91(14):1-17. Available from: http://jvi.asm.org/lookup/doi/10.1128/JVI.00163-17

44. Danthi P. Viruses and the Diversity of Cell Death. Annu Rev Virol. 2016;3(1):533-53. Available from: http://www.annualreviews.org/doi/10.1146/annurev-virology-110615-042435

45. Best SM. The Many Faces of the Flavivirus NS5 Protein in Antagonism of Type I Interferon Signaling. J Virol. 2016/11/25. 2017;91(3). Available from: https://www.ncbi.nlm.nih.gov/pubmed/27881649

46. Godoy AS, Lima GMA, Oliveira KIZ, Torres NU, Maluf F V., Guido RVC, et al. Crystal structure of Zika virus NS5 RNA-dependent RNA polymerase. Nat Commun. 2017;8:1-6. Available from: http://dx.doi.org/10.1038/ncomms14764

47. Coutard B, Barral K, Lichière J, Selisko B, Martin B, Aouadi W, et al. Zika Virus Methyltransferase: Structure and Functions for Drug Design Perspectives. J Virol. 2017;91(5):1-15.

48. Duan W, Song H, Wang H, Chai Y, Su C, Qi J, et al. The crystal structure of Zika virus NS5 reveals conserved drug targets. EMBO J. 2017;36(7):919-33. Available from: https://onlinelibrary.wiley.com/doi/abs/10.15252/embj.201696241

49. Coloma J, Jain R, Rajashankar KR, García-Sastre A, Aggarwal AK. Structures of NS5 Methyltransferase from Zika Virus. Cell Rep. 2016;16(12):3097-102. Available from: https://linkinghub.elsevier.com/retrieve/pii/S2211124716312001

50. Xu H-T, Hassounah SA, Colby-Germinario SP, Oliveira M, Fogarty C, Quan Y, et al. Purification of Zika virus RNA-dependent RNA polymerase and its use to identify small-molecule Zika inhibitors. J Antimicrob Chemother. 2017;72(3):dkw514. Available from: https://academic.oup.com/jac/articlelookup/doi/10.1093/jac/dkw514

51. Lin Y, Zhang H, Song W, Si S, Han Y, Jiang J. Identification and characterization of Zika virus NS5 RNAdependent RNA polymerase inhibitors. Int J Antimicrob Agents. 2019;(xxxx):7-11. Available from: https://doi.org/10.1016/j.ijantimicag.2019.07.010

52. Selisko B, Dutartre H, Guillemot J-C, Debarnot C, Benarroch D, Khromykh A, et al. Comparative mechanistic studies of de novo RNA synthesis by flavivirus RNA-dependent RNA polymerases. Virology. 2006;351(1):145-58. Available from: http://www.sciencedirect.com/science/article/pii/S0042682206001978 
53. Selisko B, Potisopon S, Agred R, Priet S, Varlet I, Thillier Y, et al. Molecular basis for nucleotide conservation at the ends of the dengue virus genome. PLoS Pathog. 2012/09/13. 2012;8(9):e1002912e1002912. Available from: https://www.ncbi.nlm.nih.gov/pubmed/23028313

54. Rusanov T, Kent T, Saeed M, Hoang TM, Thomas C, Rice CM, et al. Identification of a Small Interface between the Methyltransferase and RNA Polymerase of NS5 that is Essential for Zika Virus Replication. Sci Rep. 2018;8(1):17384. Available from: http://dx.doi.org/10.1038/s41598-018-35511-3

55. Xu S, Ci Y, Wang L, Yang Y, Zhang L, Xu C, et al. Zika virus NS3 is a canonical RNA helicase stimulated by NS5 RNA polymerase. Nucleic Acids Res. 2019;1-15. Available from: https://academic.oup.com/nar/advance-article/doi/10.1093/nar/gkz650/5541095

56. Klema VJ, Padmanabhan R, Choi KH. Flaviviral Replication Complex: Coordination between RNA Synthesis and 5'-RNA Capping. Viruses. 2015;7(8):4640-56. Available from: https://www.ncbi.nlm.nih.gov/pubmed/26287232

57. Kovanich D, Saisawang C, Sittipaisankul P, Ramphan S, Kalpongnukul N, Somparn P, et al. Analysis of the Zika and Japanese Encephalitis Virus NS5 Interactomes. J Proteome Res. 2019;18(8):3203-18. Available from: http://pubs.acs.org/doi/10.1021/acs.jproteome.9b00318

58. Sacramento CQ, de Melo GR, de Freitas CS, Rocha N, Hoelz LVB, Miranda M, et al. The clinically approved antiviral drug sofosbuvir inhibits Zika virus replication. Sci Rep. 2017;7(1):40920. Available from: https://www.ncbi.nlm.nih.gov/pubmed/28098253

59. King DH. History, pharmacokinetics, and pharmacology of acyclovir. J Am Acad Dermatol. 1988;18(1 Pt 2):176-9.

60. Taylor R, Kotian P, Warren T, Panchal R, Bavari S, Julander J, et al. BCX4430 - A broad-spectrum antiviral adenosine nucleoside analog under development for the treatment of Ebola virus disease. J Infect Public Health. 2016;9(3):220-6. Available from: https://linkinghub.elsevier.com/retrieve/pii/S1876034116300193

61. Eyer L, Nencka R, Huvarová I, Palus M, Alves MJ, Gould EA, et al. Nucleoside inhibitors of zika virus. J Infect Dis. 2016;214(5):707-11.

62. Bullard-Feibelman KM, Govero J, Zhu Z, Salazar V, Veselinovic M, Diamond MS, et al. The FDAapproved drug sofosbuvir inhibits Zika virus infection. Antiviral Res. 2016/11/27. 2017;137:134-40. Available from: http://www.ncbi.nlm.nih.gov/pubmed/27902933\%0Ahttp://www.pubmedcentral.nih.gov/articlerender .fcgi?artid=PMC5182171

63. Food and Drug Adminstration. Hepatitis B and C Treatments [Internet]. 2017. Available from: https://www.fda.gov/patients/hepatitis-b-c/hepatitis-b-and-c-treatments

64. Saiz J-C, Martín-Acebes MA. The Race To Find Antivirals for Zika Virus. Antimicrob Agents Chemother. 2017;61(6):1-9. Available from: http://aac.asm.org/lookup/doi/10.1128/AAC.00411-17

65. Abrams RPM, Solis J, Nath A. Therapeutic Approaches for Zika Virus Infection of the Nervous System. Neurotherapeutics. 2017;14(4):1027-48. Available from: http://link.springer.com/10.1007/s13311-0170575-2

66. Olsen DB, Eldrup AB, Bartholomew L, Bhat B, Bosserman MR, Ceccacci A, et al. A 7-deaza-adenosine analog is a potent and selective inhibitor of hepatitis $C$ virus replication with excellent pharmacokinetic properties. Antimicrob Agents Chemother. 2004;48(10):3944-53.

67. Eyer L, Valdés JJ, Gil VA, Nencka R, Hřebabecký H, Šála M, et al. Nucleoside inhibitors of tick-borne encephalitis virus. Antimicrob Agents Chemother. 2015/06/29. 2015;59(9):5483-93. Available from: https://www.ncbi.nlm.nih.gov/pubmed/26124166 
68. Schul W, Liu W, Xu H-Y, Flamand M, Vasudevan SG. A Dengue Fever Viremia Model in Mice Shows Reduction in Viral Replication and Suppression of the Inflammatory Response after Treatment with Antiviral Drugs. J Infect Dis. 2007;195(5):665-74. Available from: https://doi.org/10.1086/511310

69. Hercík K, Kozak J, Šála M, Dejmek M, Hřebabecký H, Zborníková E, et al. Adenosine triphosphate analogs can efficiently inhibit the Zika virus RNA-dependent RNA polymerase. Antiviral Res. 2017;137:131-3.

70. Zmurko J, Marques RE, Schols D, Verbeken E, Kaptein SJF, Neyts J. The Viral Polymerase Inhibitor 7Deaza-2'-C-Methyladenosine Is a Potent Inhibitor of In Vitro Zika Virus Replication and Delays Disease Progression in a Robust Mouse Infection Model. Powers AM, editor. PLoS Negl Trop Dis. 2016;10(5):e0004695. Available from: https://dx.plos.org/10.1371/journal.pntd.0004695

71. Westover JB, Mathis A, Taylor R, Wandersee L, Bailey KW, Sefing EJ, et al. Galidesivir limits Rift Valley fever virus infection and disease in Syrian golden hamsters. Antiviral Res. 2018;156(June):38-45.

72. Warren TK, Wells J, Panchal RG, Stuthman KS, Garza NL, Van Tongeren SA, et al. Protection against filovirus diseases by a novel broad-spectrum nucleoside analogue BCX4430. Nature. 2014;508:402. Available from: https://doi.org/10.1038/nature13027

73. Lim S-Y, Osuna C, Lakritz J, Chen E, Yoon G, Taylor R, et al. Galidesivir, a Direct-Acting Antiviral Drug, Abrogates Viremia in Rhesus Macaques Challenged with Zika Virus. Open Forum Infect Dis. 2017;4(suppl_1):S55-S55. Available from: https://academic.oup.com/ofid/article/4/suppl_1/S20/4293923

74. Julander JG, Siddharthan V, Evans J, Taylor R, Tolbert K, Apuli C, et al. Efficacy of the broad-spectrum antiviral compound BCX4430 against Zika virus in cell culture and in a mouse model. Antiviral Res. 2017;137:14-22. Available from: http://dx.doi.org/10.1016/j.antiviral.2016.11.003 